\title{
Evaluation of the endodontically-treated distolingual root of the mandibular first molar using cone-beam computed tomography
}

\author{
Soo-Jeong Hwang ${ }^{1}$, Sung-Joon Kim² ${ }^{2}$ and Min-Seock Seo ${ }^{3^{*}}$ \\ ${ }^{1}$ Department of Dental Hygiene, College of Medical Science, Konyang University, Daejeon 35365, Republic of Korea \\ ${ }^{2}$ Department of Dentistry, Jeju National University Hospital, Jeju 63241, Republic of Korea \\ ${ }^{3}$ Department of Conservative Dentistry, Wonkwang University Daejeon Dental Hospital, Daejeon 35233, Republic of Korea \\ (Received Jan 12, 2017; Revised version received Mar 3, 2017; Accepted Mar. 6, 2017)
}

\begin{abstract}
This retrospective study evaluated the endodontic treatment of a separate distolingual (DL) root of the mandibular first molar, using conebeam computed tomography (CBCT) images. The study included CBCT images of patients at a Korean dental college hospital. All endodontically-treated mandibular first molars having a separate DL root, were investigated. The presence of periapical lesions in the distobuccal (DB) and DL root, as well as the presence and quality of canal filling, were assessed. The differences in the quality of the root canal filling between the DL root and the DB root were analyzed using a Fisher's exact test. Multivariate logistic regression analysis separately identified the factors affecting untreated canal and adequately-filled canal of the DL root. A total of 215 mandibular first molars having a separate DL root, were found to be treated endodontically. The incidence of an untreated canal in the DL root was $28.8 \%$, whereas only $39.5 \%$ of the DL canals had an adequate canal filling. The incidence of untreated canals was significantly higher in the DL root than in the DB root $(\mathrm{p}<0.001)$. The right side was significantly associated with the presence of untreated DL canal. Adequately-filled DL canal was also associated with tooth position, and was not associated with gender, age, or the presence of a periapical lesion. The canal of DL root of the mandibular first molar was more untreated and not adequately filled, as compared to the DB canal, especially in the right side tooth.
\end{abstract}

KEY WORDS: Cone-beam computed tomography, Distolingual root, Mandibular molar, Untreated canal

\section{Introduction}

Endodontic failure is associated with the persistence of infection because of a missed canal or due to the inadequate removal of microorganisms and necrotic pulp remnants during chemo-mechanical cleaning and shaping before the performing of a root canal filling [1]. A comprehensive understanding of the presence of uncommon root canal morphology is essential for minimizing errors and is important for ensuring successful endodontic treatment.

The mandibular first molar usually has two roots (one

\section{*Corresponding author: Min-Seock Seo}

Department of Conservative Dentistry, Wonkang University Daejeon Dental Hospital, 77 Dunsan-Ro, Seo-Gu, Daejeon 35233, Republic of Korea

Tel.: +82-42-399-1142, Fax: +82-42-366-1115

E-mail: profee@wku.ac.kr mesial root and one distal root), and the distal root is typically straight with a wide oval canal or 2 round canals [2]. The most relevant variable related to the number of roots of the mandibular first molar is the presence of two separate distal roots. The presence of a separate distolingual (DL) root is not uncommon. The occurrence of a separate DL root in the mandibular first molar is associated with certain ethnic groups. A literature review showed that the prevalence of a separate DL root of the mandibular first molar falls between $0.7 \%$ and $4.2 \%$ in those of white ancestry $[3,4]$. In sub-Saharan Africans, a maximum of $2.8 \%$ was found $[5,6]$. However, in East Asian populations, the prevalence of a separate DL root of the mandibular first molars lies in the range of $10 \%-33 \%[7,8]$.

A separate DL root of the mandibular first molar deserves special attention during endodontic treatment. In radiographic imaging, the image of the distobuccal (DB) root easily superimposes over that of the DL root and is therefore unclear on those radiographs [9]. The canal in the DL 
root can be left untreated if the practitioner fails to identify its presence, which may lead to a failure of endodontic treatment. Another challenge related to the DL root of the mandibular first molar is the curvature of the root canal. The DL root is usually smaller than the DB root, and it has a sharp apical hook toward the buccal direction that is not obviously visible on radiographs $[10,11]$. Even if the practitioner notices the curvature of the root canal, the preparation procedure for a curved canal might produce ledges, apical transportation, loss of working length, perforation, and file separation [12].

As far as the authors are aware of, few studies have investigated the endodontic treatment of the DL root of the mandibular first molar. The aim of this retrospective study was thus to evaluate the endodontic treatment of this separate DL root of the mandibular first molar in a Korean dental school patient population using cone-beam computed tomography (CBCT) images.

\section{Materials and Methods}

This study was done under the approval of the Institutional Review Board of Wonkwang Dental University Daejeon Hospital. This study included the most recent CBCT image taken from 3971 patients at Wonkwang University Daejeon Dental Hospital between April 2013 and November 2016. Patients underwent these scans for a variety of reasons including implant planning, maxillofacial pathology assessment, and anatomical assessment. No patients underwent CBCT scans exclusively for this study. For each patient, age and gender were noted.

Computed tomography (CT) scans were taken using Alphard VEGA (Asahi Roentgen, Kyoto, Japan), without taking the objectives into account. The following settings were used: field of view, $512 \times 512 \mathrm{~mm} ; 80 \mathrm{kV} ; 5.00 \mathrm{~mA}$; exposure time, 17 seconds; voxel size, $0.39 \mathrm{~mm}$; and slice thickness, $1.00 \mathrm{~mm}$. Scans were viewed with the software provided with the CBCT unit, and investigators had full access to each software's image-manipulation features. Scans were viewed in a clinical environment on 24-inch monitors (resolution $1920 \times 1200$ at $60 \mathrm{~Hz}$ ).

All endodontically-treated mandibular first molars having a separate DL root were included in this study. A tooth with radiopaque material in the pulp chamber and/or root canals was considered as having been endodontically treated. Axial, sagittal, and coronal images of this DL root of the mandibular first molar were aligned to the vertical (from the canal orifice to the apex) and horizontal (from the mesial to the distal) marking lines parallel to the long axes of each canal. Initially, axial views were investigated for unfilled canal spaces. Subsequently, the findings were confirmed by examining sagittal and coronal views. Unfilled canals appearing from the cementoenamel junction to the apex were defined as being an untreated canal. The DB canal was also investigated as a reference.

An adequate root filling was defined as being a root filling contained within the tooth, terminating no more than $2 \mathrm{~mm}$ from the radiographic apex and without visible voids. A root canal which was filled more than $2 \mathrm{~mm}$ short of the radiographic apex, whether containing voids or being extruded beyond the apical foramen, was considered as being an inadequate root filling. A periapical lesion was diagnosed as being present when disruption of the lamina dura was detected and the low-density area associated with the radiographic apex was at least twice the width of the periodontal ligament space $[13,14]$.

Two pre-calibrated observers, both experienced in endodontics, screened all CBCT scans independently. Before the investigation, thirty CBCT scans not included in this study were screened for calibration purposes. Inter-observer agreement was determined using Cohen's kappa. In the event of discrepancies between the observers, both observers analyzed the images together to reach a consensus.

Statistical analyses were performed by use of the SPSS software (Statistical Package for the Social Sciences, version 17.0; IBM, Chicago, IL, USA). The differences in the quality of the root canal filling between the DL root and the DB root were analyzed using a Fisher's exact test. Multivariate logistic regression analysis was performed on the pooled data from CBCT to separately identify factors affecting the presence of an untreated canal, an adequatelyfilled canal and a periapical lesion of the DL root. The level of significance was set at $\alpha=.05$.

\section{Results}

A total of 3,971 CBCT volumes were examined. Two hundred and fifteen mandibular first molars which had a separate DL root were found to be treated endodontically. The details of patient and tooth information are listed in Table 1. The overall incidence of untreated canals in the DL root was $28.8 \%$ (62 of 215 ), and only $39.5 \%$ of the 
Table 1. Distribution of those endodontically-treated mandibular first molars with a DL root $(n=215)$

\begin{tabular}{|c|c|c|c|c|c|}
\hline \multicolumn{2}{|l|}{ Covariate } & \multicolumn{2}{|c|}{$\mathrm{N}$} & \multicolumn{2}{|c|}{$\%$} \\
\hline \multirow{2}{*}{ Gender } & Female & \multicolumn{2}{|c|}{116} & \multicolumn{2}{|c|}{54.0} \\
\hline & Male & \multicolumn{2}{|c|}{99} & \multicolumn{2}{|c|}{46.0} \\
\hline \multirow{6}{*}{ Age } & $\sim 20$ & \multicolumn{2}{|c|}{10} & \multicolumn{2}{|c|}{4.7} \\
\hline & $21 \sim 30$ & \multicolumn{2}{|c|}{81} & \multicolumn{2}{|c|}{37.7} \\
\hline & $31 \sim 40$ & \multicolumn{2}{|c|}{52} & \multicolumn{2}{|c|}{24.2} \\
\hline & $41 \sim 50$ & \multicolumn{2}{|c|}{20} & \multicolumn{2}{|c|}{9.3} \\
\hline & $51 \sim 60$ & \multicolumn{2}{|c|}{28} & \multicolumn{2}{|c|}{13.0} \\
\hline & $61 \sim$ & & & & .1 \\
\hline \multirow{3}{*}{ Tooth position } & Right & \multirow{2}{*}{\multicolumn{2}{|c|}{$\begin{array}{r}130 \\
85\end{array}$}} & \multirow{2}{*}{\multicolumn{2}{|c|}{$\begin{array}{l}60.5 \\
39.5\end{array}$}} \\
\hline & Left & & & & \\
\hline & & DB & DL & DB & DL \\
\hline \multirow{3}{*}{ Canal filling } & Untreated & 22 & 62 & 10.2 & 28.8 \\
\hline & Inadequate & 50 & 68 & 23.3 & 31.6 \\
\hline & Adequate & 143 & 85 & 66.5 & 39.5 \\
\hline \multirow{2}{*}{ Perirapical lesion } & Presence & 139 & 145 & 64.7 & 67.4 \\
\hline & Absence & 76 & 70 & 35.3 & 32.6 \\
\hline
\end{tabular}

DB: distobuccal; DL: distolingual

Table 2. Endodontic treatment of the distolingual and the distobuccal canals

\begin{tabular}{|c|c|c|c|c|}
\hline & \multicolumn{2}{|c|}{ DB Canal } & \multirow{2}{*}{ Total } & \multirow{2}{*}{$\mathrm{p}$} \\
\hline & Untreated & Treated & & \\
\hline $\begin{array}{l}\text { DL canal } \\
\text { untreated } \\
\text { treated }\end{array}$ & $\begin{array}{r}21(9.8) \\
1(0.5)\end{array}$ & $\begin{array}{r}41(19.1) \\
152(89.8)\end{array}$ & $\begin{array}{r}62(28.8) \\
153(71.2)\end{array}$ & $<0.001^{*}$ \\
\hline \multirow[t]{3}{*}{ Total } & $22(10.2)$ & 193(89.8) & $215(100.0)$ & \\
\hline & \multicolumn{2}{|c|}{ DB canal } & Total & \\
\hline & Inadequate & Adequate & Total & $\mathrm{p}$ \\
\hline $\begin{array}{l}\text { DL canal } \\
\text { inadequate } \\
\text { adequate }\end{array}$ & $\begin{array}{r}30(19.7) \\
3(2.0)\end{array}$ & $\begin{array}{l}38(25.0) \\
81(53.3)\end{array}$ & $\begin{array}{l}68(44.7) \\
84(55.3)\end{array}$ & $<0.001^{*}$ \\
\hline Total & $33(21.7)$ & $119(78.3)$ & $152(100.0)$ & \\
\hline
\end{tabular}

*: Statistically significant; DB: distobuccal; DL: distolingual
DL canals had an adequate canal filling. The incidence of untreated canals was significantly higher in the DL root than in the DB root $(\mathrm{p}<0.001)$. Also, the incidence of inadequate canal fillings was significantly higher in the $\mathrm{DL}$ root than in the DB root $(\mathrm{p}<0.001)$ (Table 2$)$.

Because the odds ratio (OR) provides a good estimate of the relative risk, we showed the OR derived from multivariate logistic regression analysis (Table 3-5). The right position [OR 2.37, 95\% confidence interval (CI): 1.105.10] and untreated canal filling of the DB root (OR 95.50, 95\% CI 12.00-759.97) were significantly associated with the presence of untreated DL canal (Table 3). Table 4 shows the significant association between adequately filled DL canal and DB canal. Adequately filled DL canal was also associated with tooth position (a rightside OR of 0.46 , with a $95 \%$ CI of $0.22-1.00$ ), and was not associated with gender, age, or the presence of a periapical lesion. The presence of a DB apical lesion (an OR of 23.57, with a $95 \%$ CI of 10.77-51.55) showed a significant association with the presence of a DL apical lesion (Table 5).

Inter-observer agreement was determined and Cohen's kappa was calculated for different parameters. Cohen's kappa was 0.9 for periapical lesion, 0.9 for untreated canal, 0.8 for adequate canal filling, and 0.7 for inadequate canal filling. These results show that Cohen's kappa was high and inter-observer agreement of this study can be considered good [15].

\section{Discussion}

The purpose of this study was to investigate the end-

Table 3. Logistic regression analysis for assessing the association of selected covariates with an untreated DL canal

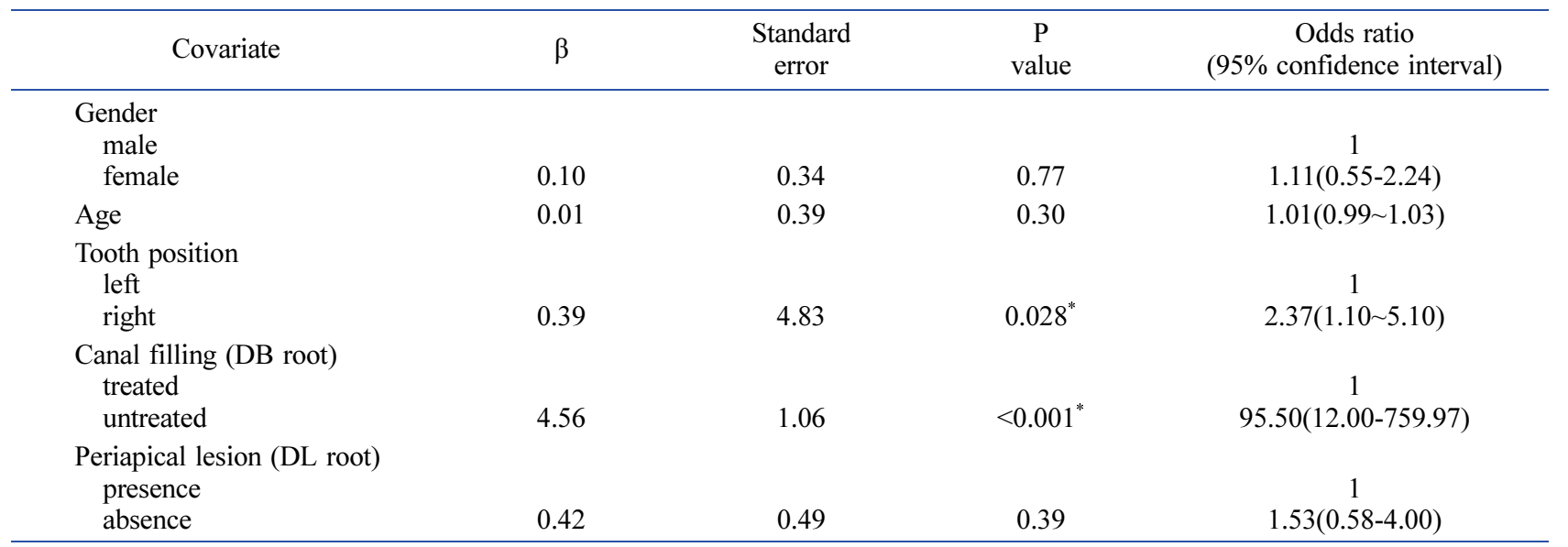

\footnotetext{
*: Statistically significant; DB: distobuccal; DL: distolingual
} 
Soo-Jeong Hwang et al.

Table 4. Logistic regression analysis for assessing the association of selected covariates with an adequately-filled DL canal (153 cases)

\begin{tabular}{|c|c|c|c|c|}
\hline Covariate & $\beta$ & $\begin{array}{l}\text { Standard } \\
\text { error }\end{array}$ & $\begin{array}{c}\mathrm{P} \\
\text { value }\end{array}$ & $\begin{array}{l}\text { Odds ratio } \\
(95 \% \text { confidence interval })\end{array}$ \\
\hline $\begin{array}{l}\text { Gender } \\
\text { male } \\
\text { female }\end{array}$ & -0.32 & 0.38 & .40 & $\begin{array}{c}1 \\
0.73(0.34-1.53)\end{array}$ \\
\hline Age & 0.001 & 0.01 & .94 & $1.00(0.98-1.03)$ \\
\hline $\begin{array}{l}\text { Tooth position } \\
\text { left } \\
\text { right }\end{array}$ & -0.77 & 0.39 & $.049^{*}$ & $\begin{array}{c}1 \\
0.46(0.22-1.00)\end{array}$ \\
\hline $\begin{array}{l}\text { Canal filling (DB canal) } \\
\text { inadequate } \\
\text { adequate }\end{array}$ & 2.82 & 0.59 & $<0.001^{*}$ & $\begin{array}{c}1 \\
16.75(5.25-53.48)\end{array}$ \\
\hline $\begin{array}{l}\text { Periapical lesion (DL root) } \\
\text { presence } \\
\text { absence }\end{array}$ & 0.22 & 0.55 & .69 & $\begin{array}{c}1 \\
1.24(0.42-3.64)\end{array}$ \\
\hline
\end{tabular}

*: Statistically significant; DB: distobuccal; DL: distolingual

Table 5. Logistic regression for the association of some covariates with the presence of a DL periapical lesion

\begin{tabular}{lcccc}
\hline \multicolumn{1}{c}{ Covariate } & $\beta$ & $\begin{array}{c}\text { Standard } \\
\text { error }\end{array}$ & $\begin{array}{c}\text { P } \\
\text { value }\end{array}$ & $\begin{array}{c}\text { Odds ratio } \\
\text { (95\% confidence interval) }\end{array}$ \\
\hline $\begin{array}{l}\text { Gender } \\
\text { male } \\
\text { female }\end{array}$ & & & 1 \\
$\quad \begin{array}{l}\text { Age } \\
\text { Tooth position }\end{array} \quad-0.37$ & 0.39 & .33 & $0.69(0.32-1.47)$ \\
$\quad$ left & 0.01 & 0.01 & .26 & $1.01(0.99-1.04)$ \\
$\quad$ right & & & $0.92(0.42-2.00)$ \\
$\quad \begin{array}{l}\text { Canal filling (DL canal) } \\
\quad \text { untreated }\end{array}$ & -0.09 & 0.40 & .82 & 1 \\
$\quad$ inadequate & & & $0.69(0.24-2.02)$ \\
$\quad$ adequate & -0.37 & 0.55 & .50 & $0.62(0.21-1.84)$ \\
$\quad \begin{array}{l}\text { Periapical lesion (DB root) } \\
\quad \text { presence } \\
\quad \text { absence }\end{array}$ & -0.48 & 0.56 & .39 & 1 \\
\hline
\end{tabular}

*: Statistically significant; DB: distobuccal; DL: distolingual

odontic treatment of the DL root of the mandibular first molar (which is known to be difficult to treat endodontically); to compare the result with the DB root as a control; and to statistically evaluate a range of various factors. This study was done using CBCT images obtained from patients who visited dental school hospital. A limitation of collecting data retrospectively, as in this study, is that such a study cannot fully cover all the potential causal factors which influence the treatment and the outcome. Such factors potentially include treatment time, qualifications of the practitioner, quality of the cleaning procedure, treatment methodology, and quality of restoration. In this study, referral rationale, along with the reasons for the taking of the CBCT, was not documented. The age of the patients in this study was documented at the time the CBCT was taken, because the actual date of endodontic treatment could not be known. There were no significant differences with regards to patient age.

It is controversial whether the incidence of there being a DL root of the mandibular first molars is high on either the right or the left side of those molars. In one study on Chinese population, the DL root of the mandibular first molar was found to more frequently be located on the left side as compared to the right [16]. However, studies of Taiwanese and Koreans reported that the DL root was found more on the right side than on the left $[8,17,18]$. On the other hand, another studies reported that there was no significant difference between the right and the left side $[19,20]$. The general incidence of there being a DL root of the mandibular first molar cannot be drawn from this study. Even so, however, among the endodontically-treated mandibular first molars with a DL root, the percentage of 
right side $(60.5 \%)$ was higher than that of left side $(39.5 \%)$. This seems to be consistent with the findings of studies of Koreans - studies that reported the higher prevalence of the DL root on the right side of the mandibular first molars $[17,18]$.

Generally, the left/ right position of the mandibular first molars has not been distinguished to evaluate treatment results in the field of endodontics. Even if it was distinguished, there was no significant difference related to the right/ left position [21]. In other field of dental treatments, however, some studies have reported differences in outcomes related to the left/ right position. According to the studies that investigated the factors affecting the clinical success of screw implants used as orthodontic anchorage, the left side had a higher success rate than did the right side [22, 23]. Pandis et al. investigated the failure rate of molar tubes bonded to molars and reported that right-sided tubes demonstrated 3 times more failures when compared to left-sided tubes [24]. In this study, the incidence of an untreated DL canal was significantly higher and the incidence of adequately filled DL canal was significantly lower in the right-side (versus the left-side) mandibular first molar. The practitioner usually sits on the right side of the patient and treats to the left, so he or she may have some difficulty in treating the patient's right posterior teeth. This tendency can be even more severe when there is a narrow, curved root canal in either of the right molars. This study shows that when the practitioners perform endodontic treatment of the DL root of the mandibular first molar, the right side tooth is more difficult to treat than the left one is.

Clinically, an untreated canal is one of the major reasons for post-endodontic treatment disease [1]. Failure to recognize the presence of a DL root during root canal treatment may lead to incomplete removal of the root canal system and eventually result in treatment failure. This study shows that the DL root of the mandibular first molar is more difficult to treat endodontically than the DB root is. For the DL root, the percentage of canals that were left endodontically-untreated was higher; and the rate of adequately-filled canals was also lower than that of the DB root. It has been found in several studies that the root canal of the DL root is morphologically special. The canal orifice of the DL root is located disto- to mesiolingually from the main canal or canals in the distal root [25]. According to a micro CT study, the mean inter-orifice length between the mesiobuccal (MB) and mesiolingual (ML) canal $(2.48 \mathrm{~mm})$ was shorter than that between the
DB and the DL canal $(2.93 \mathrm{~mm})$ [26]. Other CBCT studies also reported that the distance between the DB-DL canal entrance was $2.72 \mathrm{~mm}$ long [8]. Therefore, an extension of the traditional triangular opening cavity should be extended to the lingual area [25]. In other words, to expose the orifice of the DL canal, the access form needs to be modified into a trapezoidal shape. In older patients, it may be more difficult to locate the canal orifice of the DL root due to calcification of the canal. However, the results of this study showed no significant difference with regards to the age of patients.

Not only does the location of the canal orifice make it difficult to treat endodontically, but the curvature of the DL canal also adds to this difficulty. One micro-CT study reported that the canal curvature of the DL root has a more severe angle and a smaller radius in the proximal view than in the clinical view-and that the length of the curved portion is relatively long [26]. The root canal of the DL root does not show a large curvature in periapical radiograph imaging, but it does have a large curvature in the buccolingual (BL) direction. Therefore, it is prone to several procedural errors during endodontic treatment. Another CBCT study reported that maximum canal curvature was observed most frequently in the apical third of the canal in the BL direction [10]. According to the other micro-CT study, most DL roots had a buccally-displaced apical foramen [27]. These features are the reason why the canal of the DL root is not adequately filled during endodontic treatment as compared with the canal of the DB root. For this reason, practitioner should be prepared to deal with the challenge like this case. To gain access to the apical portion of the DL root canal, coronal flaring is recommended to decrease the angle of curvature [26]. It is very important for successful shaping of the DL root canal to avoid over-instrumentation and fatigue failure of endodontic files.

So far, there have been many studies regarding the DL root of the mandibular first molar in terms of its morphology and incidence, but it is true that there is a lack of research on how to approach or how to prepare the root canal of the DL root. Further studies on the practical endodontic treatment of the DL root of the mandibular first molar are needed.

\section{Conclusions}

Among endodontically-treated mandibular first molars 
which had a separate DL root, the DL canals were left significantly untreated and not adequately filled than the DB canals. When comparing the DL root of the left and right teeth, the incidences of the canal being left untreated and not adequately filled were both higher for the right, rather than the left, mandibular first molar. Therefore, if the practitioner notices a separate DL root of the mandibular first molar during endodontic treatment especially on the right side, he or she should try hard to find the root canal orifice, and should treat it with special care.

\section{Conflict of Interest}

The authors declare that they have no competing interests.

\section{ORCID}

Soo-Jeong Hwang 0000-0003-4725-1512

Sung-Joon Kim 0000-0003-0603-4036

Min-Seock Seo 0000-0001-7203-7775

\section{References}

1. Hargreaves KM, Cohen S. Cohen's Pathways of the Pulp. 10th ed. St. Louis: Mosby; 2010.

2. Skidmore AE, Bjorndal AM. Root canal morphology of the human mandibular first molar. Oral Surg Oral Med Oral Pathol 1971;32:778-784. doi: http://dx.doi.org/ 10.1016/0030-4220(71)90304-5.

3. Curzon ME. Three-rooted mandibular permanent molars in English Caucasians. J Dent Res 1973;52:181. doi: http:/journals.sagepub.com/doi/pdf/10.1177/00220345730520011901.

4. Schäfer E, Breuer D, Janzen S. The Prevalence of threerooted mandibular permanent first molars in a German population. J Endod 2009;35:202-205. doi: http://dx.doi.org/ 10.1016/j.joen.2008.11.010.

5. Sperber GH, Moreau JL. Study of the number of roots and canals in Senegalese first permanent mandibular molars. Int Endod J 1998;31:117-122. doi: 10.1046/j.1365-2591. 1998.00126.x.

6. Younes SA, al-Shammery AR, el-Angbawi MF. Threerooted permanent mandibular first molars of Asian and black groups in the Middle East. Oral Surg Oral Med Oral Pathol 1990;69:102-105. doi: http://dx.doi.org/ 10.1016/0030-4220(90)90276-X.

7. Loh HS. Incidence and features of three-rooted permanent mandibular molars. Aust Dent J 1990;35:434-437. doi: 10.1111/j.1834-7819.1990.tb05426.x.

8. Tu MG, Huang HL, Hsue SS, Hsu JT, Chen SY, Jou MJ, Tsai CC. Detection of permanent three-rooted mandibular first molars by cone-beam computed tomography imaging in Taiwanese individuals. J Endod 2009;35:503507. doi: 10.1016/j.joen.2008.12.013.

9. Jerome CE, Hanlon RJ Jr. Dental anatomical anomalies in Asians and Pacific Islanders. J Calif Dent Assoc 2007;35:631-636.

10. Choi MR, Moon YM, Seo MS. Prevalence and features of distolingual roots in mandibular molars analyzed by cone-beam computed tomography. Imaging Sci Dent 2015;45:221-226. doi: 10.5624/isd.2015.45.4.221.

11. De Moor RJ, Deroose CA, Calberson FL. The radix entomolaris in mandibular first molars: an endodontic challenge. Int Endod J 2004;37:789-799. doi: 10.1111/ j.1365-2591.2004.00870.x.

12. Peters OA. Current challenges and concepts in the preparation of root canal systems: a review. J Endod 2004; 30:559-567. doi: 10.1097/01.DON.0000129039.59003.9D.

13. Abella F, Patel S, Duran-Sindreu F, Mercadé M, Bueno R, Roig M. Evaluating the periapical status of teeth with irreversible pulpitis by using cone-beam computed tomography scanning and periapical radiographs. J Endod 2012;38:1588-1591. doi: 10.1016/j.joen.2012.09.003.

14. Zhang MM, Liang YH, Gao XJ, Jiang L, van der Sluis L, Wu MK. Management of apical periodontitis: healing of post-treatment periapical lesions present 1 year after endodontic treatment. J Endod 2015;41:1020-1025. doi: 10.1016/j.joen.2015.02.019.

15. Altman DG. Practical statistics for medical research. 1st ed. London: Chapman \& Hall; 1991.

16. Wang Y, Zheng QH, Zhou XD, Tang L, Wang Q, Zheng GN, Huang DM. Evaluation of the root and canal morphology of mandibular first permanent molars in a western Chinese population by cone-beam computed tomography. J Endod 2010;36:1786-1789. doi: 10.1016/j.joen.2010.08. 016.

17. Song JS, Choi HJ, Jung IY, Jung HS, Kim SO. The prevalence and morphologic classification of distolingual roots in the mandibular molars in a Korean population. $\mathrm{J}$ Endod 2010;36:653-657. doi: 10.1016/j.joen.2009.10.007.

18. Kim SY, Yang SE. Cone-beam computed tomography study of incidence of distolingual root and distance from distolingual canal to buccal cortical bone of mandibular first molars in a Korean population. J Endod 2012; 38:301-304. doi: 10.1016/j.joen.2011.10.023.

19. Garg AK, Tewari RK, Kumar A, Hashmi SH, Agrawal N, Mishra SK. Prevalence of three-rooted mandibular permanent first molars among the Indian Population. J Endod 2010;36:1302-1306. doi: 10.1016/j.joen.2010.04.019.

20. Huang RY, Cheng WC, Chen CJ, Lin CD, Lai TM, Shen EC, Chiang CY, Chiu HC, Fu E. Three-dimensional analysis 
of the root morphology of mandibular first molars with distolingual roots. Int Endod J 2010;43:478-484. doi: 10.1111/j.1365-2591.2010.01702.x.

21. Song M, Kim SG, Lee SJ, Kim B, Kim E. Prognostic factors of clinical outcomes in endodontic microsurgery: A Prospective Study. J Endod 2013;39:1491-1497. doi: 10.1016/j.joen.2013.08.026.

22. Park HS, Jeong SH, Kwon OW. Factors affecting the clinical success of screw implants used as orthodontic anchorage. Am J Orthod Dentofacial Orthop 2006;130: 18-25. doi:10.1016/j.ajodo.2004.11.032.

23. Wu TY, Kuang SH, Wu CH. Factors associated with the stability of mini-implants for orthodontic anchorage: a study of 414 samples in Taiwan. J Oral Maxillofac Surg 2009;67:1595-1599. doi: 10.1016/j.joms.2009.04.015.

24. Pandis N, Polychronopoulou A, Eilades T. A compara- tive assessment of the failure rate of molar tubes bonded with a self-etching primer and conventional acid-etching. World J Orthod 7:41-44.

25. Calberson FL, De Moor RJ, Deroose CA. The radix entomolaris and paramolaris: clinical approach in endodontics. J Endod 2007;33:58-63. doi: 10.1016/j.joen.2006. 05.007.

26. Gu Y, Lu Q, Wang H, Ding Y, Wang P, Ni L. Root canal morphology of permanent three-rooted mandibular first molars--part I: pulp floor and root canal system. J Endod 2010;36:990-994. doi: 10.1016/j.joen.2010.02.030.

27. Souza-Flamini LE, Leoni GB, Chaves JF, Versiani MA, Cruz-Filho AM, Pécora JD, Sousa-Neto MD. The radix entomolaris and paramolaris: a micro-computed tomographic study of 3-rooted mandibular first molars. J Endod 2014;40:1616-1621. doi: 10.1016/j.joen.2014.03.012. 